\title{
Misdiagnosis of chronic pulmonary aspergillosis as pulmonary tuberculosis at a tertiary care center in Uganda: a case series
}

Richard Kwizera ${ }^{1,2^{*}} \mathbb{D}$, Andrew Katende ${ }^{3}$, Felix Bongomin ${ }^{4}$, Lydia Nakiyingi ${ }^{1,3}$ and Bruce J. Kirenga 2,3

\begin{abstract}
Background: Diagnosis of chronic pulmonary aspergillosis (CPA) is based on a combination of clinical symptomatology, compatible chest imaging findings, evidence of Aspergillus infection and exclusion of alternative diagnosis, all occurring for more than 3 months. Recently, a rapid, highly sensitive and specific point-of-care lateral flow device (LFD) has been introduced for the detection of Aspergillus-specific immunoglobulin (lg)G, especially in resource-limited settings where CPA is underdiagnosed and often misdiagnosed as smear-negative pulmonary tuberculosis (PTB). Therefore, in our setting, where tuberculosis (TB) is endemic, exclusion of PTB is an important first step to the diagnosis of CPA. We used the recently published CPA diagnostic criteria for resource-limited settings to identify patients with CPA in our center.

Case presentation: Three Ugandan women (45/human immunodeficiency virus (HIV) negative, 53/HIV infected and 18/HIV negative), with a longstanding history of cough, chest pain, weight loss and constitutional symptoms, were clinically and radiologically diagnosed with PTB and empirically treated with an anti-tuberculous regimen despite negative microbiological tests. Repeat sputum Mycobacteria GeneXpert assays were negative for all three patients. On further evaluation, all three patients met the CPA diagnostic criteria with demonstrable thick-walled cavities and fungal balls (aspergilomas) on chest imaging and positive Aspergillus-specific lgG/lgM antibody tests. After CPA diagnosis, anti-TB drugs were safely discontinued for all patients, and they were initiated on capsules of itraconazole 200 mg twice daily with good treatment outcomes.
\end{abstract}

Conclusions: The availability of simple clinical diagnostic criteria for CPA and a LFD have the potential to reduce misdiagnosis of CPA and in turn improve treatment outcomes in resource-limited settings.

Keywords: Chronic pulmonary aspergillosis, Lateral flow device, Aspergillus-specific lgG, Diagnosis, Resource-limited settings, Case report

\section{Background}

Tuberculosis (TB) is one of the most common causes of death and the leading cause of death from a single infectious agent worldwide. The highest burden is found in Africa and Asia mostly linked to the human

*Correspondence: kwizerarichard@ymail.com

${ }^{1}$ Department of Research, Infectious Diseases Institute, College of Health Sciences, Makerere University, P.O.BOX, 22418 Kampala, Uganda

Full list of author information is available at the end of the article immunodeficiency virus (HIV) epidemic in these regions [1]. The 2020 World Health Organization (WHO) report on TB showed that globally 10 million people developed TB in 2019, with an estimated 1.2 million deaths among HIV-negative people and an additional 208,000 deaths from TB among HIV-positive people [2]. Due to residual lung damage, pulmonary tuberculosis (PTB) is an important risk factor for other chronic respiratory diseases including chronic obstructive pulmonary disease (COPD), bronchiectasis and aspergillosis [3]. original author(s) and the source, provide a link to the Creative Commons licence, and indicate if changes were made. The images or other third party material in this article are included in the article's Creative Commons licence, unless indicated otherwise in a credit line to the material. If material is not included in the article's Creative Commons licence and your intended use is not permitted by statutory regulation or exceeds the permitted use, you will need to obtain permission directly from the copyright holder. To view a copy of this licence, visit http://creativecommons.org/licenses/by/4.0/. The Creative Commons Public Domain Dedication waiver (http://creativeco mmons.org/publicdomain/zero/1.0/) applies to the data made available in this article, unless otherwise stated in a credit line to the data. 
Chronic pulmonary aspergillosis (CPA) is a slowly progressive and destructive parenchymal lung disease mostly caused by Aspergillus fumigatus [4] and affecting both immunocompetent and immunocompromised patients commonly with previous or underlying lung diseases [5]. CPA affects an estimated 3 million people worldwide [6, 7] and 62,000 people in Uganda [8]. More than half of cases of CPA occur as a complication of treated PTB; CPA and PTB can co-exist, posing a challenge in distinguishing the two clinically and on radiology [9]. This group of patients is often misdiagnosed and managed as smear-negative PTB $[10,11]$. With the high burden of PTB in Uganda, mostly being secondary to HIV $[2,12]$, the incidence of CPA is probably higher but the index of clinical suspicion for CPA is very low [13]. This may be partly contributed by the shortage of diagnostic capabilities due to lack of local capacity for mycology. Recently, two diagnostic algorithms have been published to facilitate the diagnosis of CPA in resource-constrained settings $[14,15]$, with emphasis on the exclusion of mycobacterial infections as an important alternative diagnosis in resource-limited settings.

Based on the unified case definition of CPA in resourcelimited settings [14], and the point-of-care test, our index of clinical suspicion recently increased, and we started identifying more cases of CPA in our pulmonology wards at Kiruddu National Referral Hospital in Kampala which were previously clinically misdiagnosed and managed as PTB $[16,17]$. Herein, we report three cases of CPA that were previously misdiagnosed as PTB in routine clinical practice in a resource-limited setting, using a simple clinical algorithm and the recently validated Aspergillus LFD (LDBio Diagnostic, Lyon, France) [18]. This article was written following the CARE Checklist of information to include when writing a case report (Additional file 1).

\section{Case presentations}

\section{Case I}

A 45-year-old Ugandan woman presented with a 3-month history of coughing up blood-stained sputum associated with left-sided pleuritic chest pain, exacerbated by lying on the same side. This was the first episode of hemoptysis. She reported mild dizziness, but no exertional intolerance, orthopnea or ankle swellings. She had no history of constitutional symptoms. She was a peasant farmer who resided in a rural area and was referred from a peripheral health facility where she had been suspected to have TB and was started on anti-TB therapy for 14 days. She was HIV negative and had no history of previous chronic chest symptoms. She was not a current or ex-smoker of tobacco.

On examination, her blood pressure was 120/80 $\mathrm{mmHg}$, pulse rate 80 beats per minute (bpm), peripheral oxygen saturation $\left(\mathrm{SpO}_{2}\right) 98 \%$ on ambient air, respiratory rate $24 \mathrm{bpm}$ and temperature $36.8^{\circ} \mathrm{C}$. She had no conjunctivae pallor, jaundice or lymphadenopathy. On chest examination, she was tachypneic with mild respiratory distress. She had reduced chest movements on the left with increased tactile fremitus, dull percussion notes and bronchial breathing in the left infraclavicular region. The trachea was deviated to left with the apex beat displaced to the sixth intercostal space (ICS). There were coarse crepitations on the left axillary region. The remainder of the examinations was unremarkable.

Chest $\mathrm{x}$-ray showed an intracavitary mass crowned with cresenteric lucency in the left upper zones; the lower zones were dense with fibrotic bands with an associated mediastinal shift to the ipsilateral side and contralateral lung hyperinflation (Fig. 1a). Chest computed tomography $(\mathrm{CT})$ scan showed a cavitating lesion containing a soft tissue density mass with massive architectural distortion. The pleura appeared thickened, and there was herniation of the contralateral lung to the left due to volume loss (Fig. 1b).

The complete blood count was normal. Sputum GeneXpert was negative for Mycobacterium tuberculosis. Renal and liver function tests were within normal limits. Aspergillus-specific LFD (immunoglobulin (Ig)G/IgM) was positive (Fig. 1c). She had a normal resting electrocardiogram, and echocardiography was of a heart with normal function and structure. A diagnosis of chronic fibrosing and cavitary aspergillosis was made. Anti-TB drugs were stopped, and oral itraconazole $200 \mathrm{mg}$ twice daily was initiated for a minimum duration of 6 months. The patient is alive and doing well and still attends the pulmonology clinic. We had planned to do a control $\mathrm{x}$-ray a few weeks later, but the patient feared traveling back because of the outbreak of the COVID-19 pandemic at that time.

\section{Case II}

A 53-year-old Ugandan woman with a long-standing history of cough presented with a worsening cough over the past 2 weeks. Her cough was productive of a copious brownish foul-smelling sputum that was nonblood-stained associated with right pleuritic chest pain, low-grade fevers, anorexia, marked weight loss and excessive night sweats. She also reported difficulty in breathing on exertion and on lying flat, but showed no lower limb swelling. She was a food vendor in a taxi park who resided in an urban area and had been diagnosed with HIV infection 11 years previously and had been on dolutegravir/lamivudine/tenofovir (DTG/3TC/TDF) for 4 months. Recent CD4 T-counts and viral loads were not known. We did not perform CD4 at that time point. Review of other systems was essentially normal. She was 


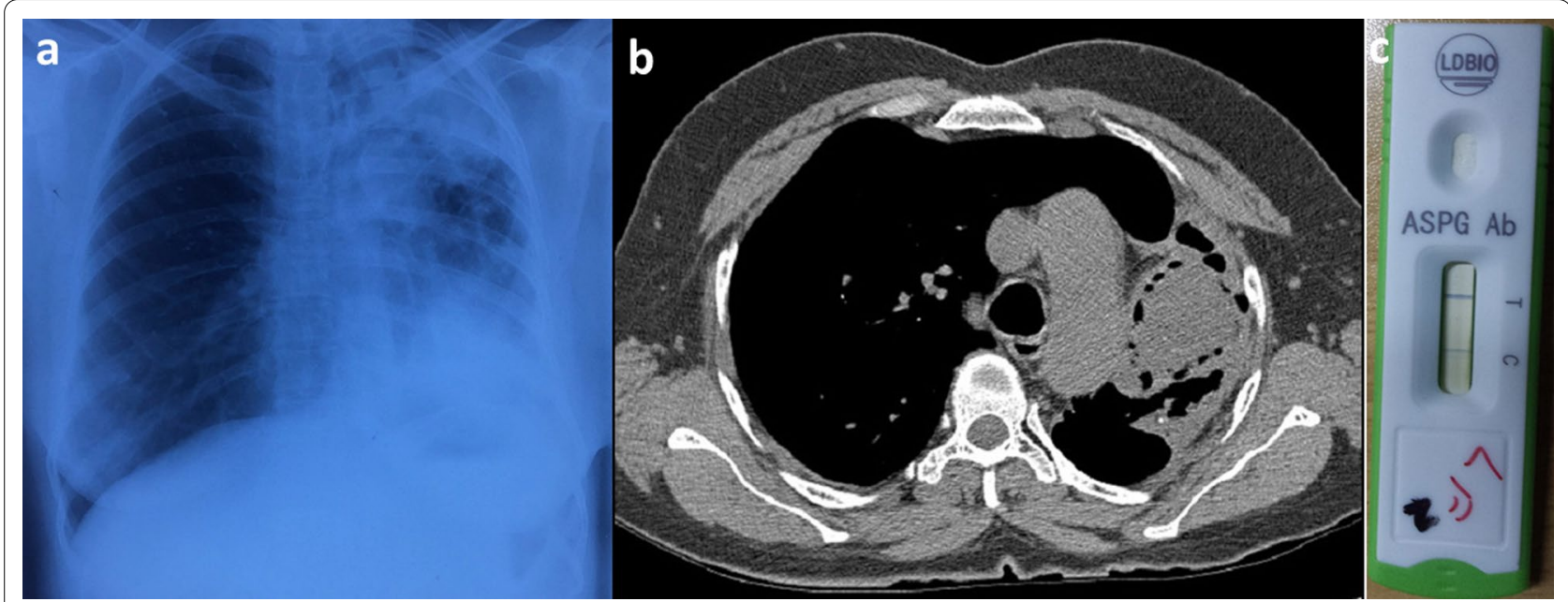

Fig. 1 Case 1. a Chest x-ray showing a mass in the left upper lung zones with an "air crescent sign" and fibrotic changes in the lower zones. b Chest CT scan showing an ovoid mass surrounded by pockets of air, most probably a fungal ball with local pleural thickening. c Positive Aspergillus $\operatorname{lgM}-\lg G \mathrm{LFD}$

diagnosed and treated four times (6 months each time) for PTB. She had a history of frequent childhood respiratory symptoms of cough and difficulty in breathing, and she was told she suffered from asthma. However, she had no previous documentation and had never used inhaler therapies. She had previously smoke the local tobacco for 2 years and had occasionally used alcohol for 1 year.

On examination, she had a BP of $120 / 80 \mathrm{mmHg}$, pulse rate $80 \mathrm{bpm}$ (regular), respiratory rate $22 \mathrm{bpm}$ and $\mathrm{SpO}_{2}$ $98 \%$ on room air. She was wasted with mild pallor of the mucous membrane with digital clubbing. She had no jaundice, edema or lymphadenopathy. On chest examinations, she had mild respiratory distress. She had a flattened right-side chest in the infraclavicular region with reduced chest movements, tracheal deviation to the right and apex beat of the sixth intercostal space (ICS). In the same chest region, there was increased tactile fremitus, a dull percussion note, bronchial breathing and increased vocal resonance. Cardiac and abdominal examinations were normal.

Chest $\mathrm{x}$-ray showed a thick walled cavity with irregular margins containing an intracavitary mass in the right middle zones with perilesional patchy opacities (Fig. 2a). Chest CT scan was not done for this patient. All other laboratory findings were normal apart from the positive Aspergillus IgM-IgG LFD (Fig. 2b). The patient was started on oral itraconazole $200 \mathrm{mg}$ twice a day. The patient later died in another hospital.

\section{Case III}

An 18-year-old Ugandan woman, HIV negative, presented with a 2-month history of progressive productive cough, non-blood-stained sputum associated with rightsided pleuritic chest pain exacerbated on coughing and occasional difficulty breathing. She also had associated high-grade fevers, anorexia and marked weight loss but no excessive night sweats. She had no orthopnea or paroxysmal nocturnal dyspnea or lower limb swelling. She was a student who resided in a rural area and was treated for PTB two times in 2017 and 2018 with completion of treatment (6 months for each time).

On examination, she had a blood pressure of 110/70 $\mathrm{mmHg}$, respiratory rate 22 breaths per minute, pulse rate 131 beats per minute and $\mathrm{SpO}_{2} 94 \%$ on room air. She was febrile with a temperature of $38.3{ }^{\circ} \mathrm{C}$. She was severely pale with no digital clubbing. She had no palpable lymph nodes and no edema. Chest examination revealed a flattened right infraclavicular region with tracheal deviation to the right without displacement of the point of maximum cardiac intensity. There were reduced chest movements on the right hemithorax, with an increased tactile fremitus, dull percussion note and broncho-breathing both posteriorly in the mid-scapular area and in the anterior mammary area. Cardiac examination revealed tachycardia with normal heart sounds.

Chest $\mathrm{x}$-ray showed a homogeneous opacity in the right hemithorax with multiple crowded cysts in the middle and lower lung zones associated with volume loss and ipsilateral mediastinal shift. There was a cavity in the right perihilar region. There were multiple reticulonodular opacities scattered throughout the entire right lung field with cystic changes (Fig. 3a). The chest CT scan showed a thick-walled cavity with an intracavitary nodule in the lingula segment in the lung window. The 


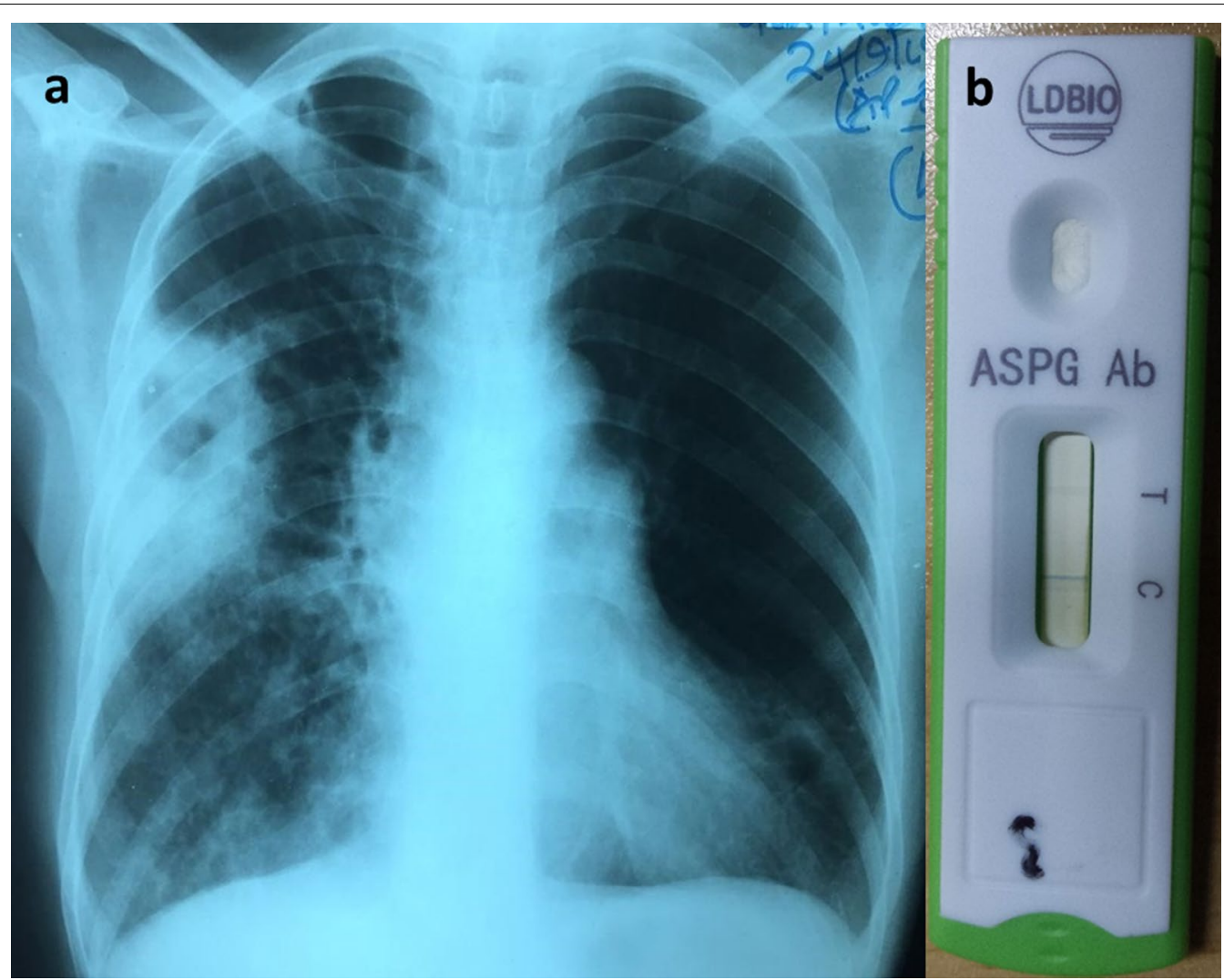

Fig. 2 Case 2. a Chest x-ray showing a thick-walled cavity with an intrinsic mass in the right middle zone surrounded with patchy opacities medially and inferiorly. b Positive Aspergillus lgM-lgG LFD

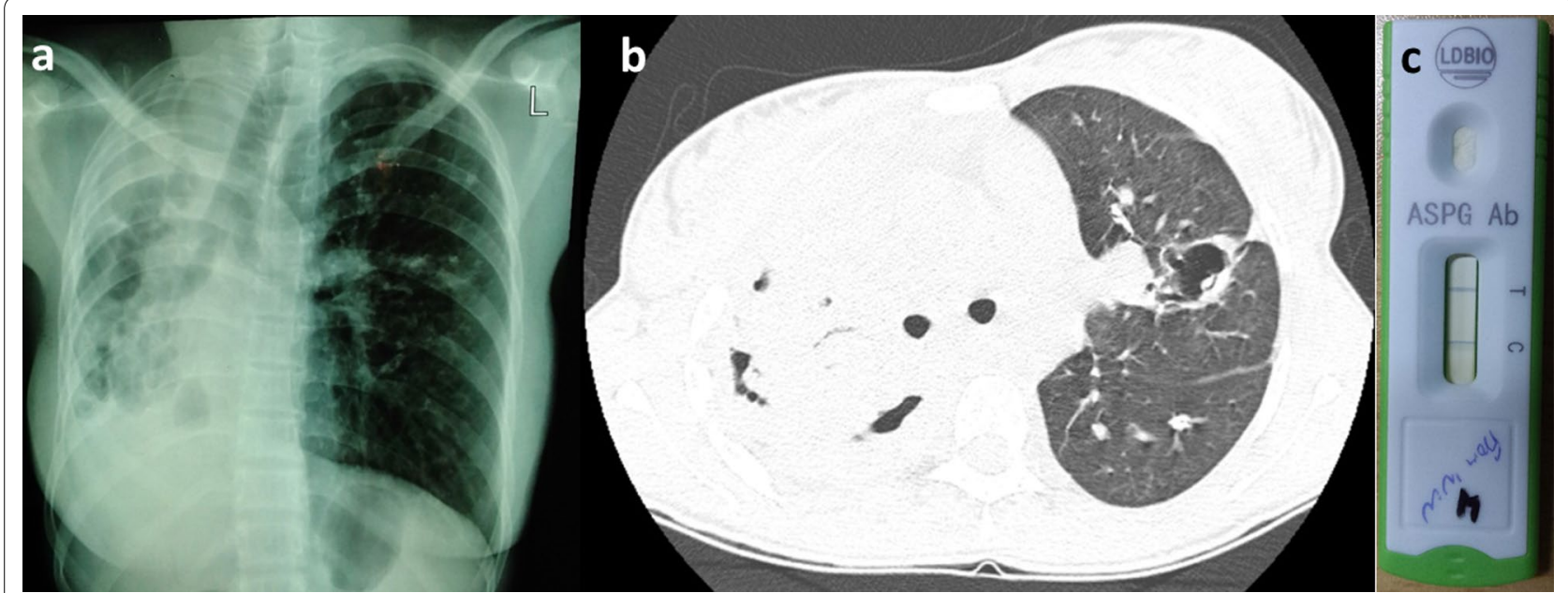

Fig. 3 Case 3. a Chest x-ray showing post-inflammatory fibrotic changes in the right lung with features of bronchiectasis on the left with a left perihilar cavity. b Chest CT scan showing a thick-walled cavity with an intracavitary nodule and bronchiectasis. c Positive Aspergillus IgM-lgG LFD

mediastinal window had a soft tissue density in the right lung field with intrinsic dilated bronchioles. The mediastinum was deviated to the right (Fig. 3b).
Complete blood count showed a leukocytosis, neutrophilia and microcytic anemia. Sputum GeneXpert was negative for Mycobacterium tuberculosis. Renal and liver 
function tests were within normal limits. Aspergillusspecific LFD (IgG-IgM) was positive (Fig. 3c). Diagnosis of chronic fibrosing pulmonary aspergillosis with a superimposed bacteremia was made. Oral itraconazole $200 \mathrm{mg}$ twice a day was initiated together with intravenous ceftriaxone $1 \mathrm{~g}$ and levofloxacin $500 \mathrm{mg}$ once a day. She was also transfused with 1 unit of whole blood. She developed superior vena cava obstruction (SVCO) and Horner's syndrome from an aneurysm. We referred her to another private referral hospital for respiratory support and cardiothoracic surgery where she later died.

\section{Discussion and conclusion}

According to the unified case definition of CPA in resource-limited settings [14], CPA can be defined as "illness of $\geq 3$ months and all of: (1) weight loss, persistent cough and/or haemoptysis; (2) chest images showing progressive cavitary infiltrates and/or a fungal ball and/ or pericavitary fibrosis or infiltrates or pleural thickening; and (3) a positive Aspergillus IgG assay or other evidence of Aspergillus infection." A recent publication from our setting [17] showed that we could diagnose CPA in routine clinical practice in a resource-limited setting using a lateral flow device [19-21] as the third criterion (evidence of Aspergillus infection) after exclusion of an alternative diagnosis. The LDBio Aspergillus LFD has a sensitivity of $92 \%$ and a specificity of $98.0 \%$ in patients with proven CPA [18]. In this study, patients I and III represent typical cases of CPA. Patient I was initiated on anti-TB medication based on clinical suspicion without microbiological evidence of PTB. Previous studies have shown that almost $35 \%$ of subjects with CPA might be wrongly treated with anti-TB medication despite the lack of microbiological evidence [22]. This is also very common in resource-limited settings where the index of clinical suspicion for fungal infections is very low $[13,23]$ and the diagnostic capacity for mycoses is lacking. A recent paper from our setting showed that "using freely available online materials on medical mycology can enhance teaching and learning of medical mycology" [24].

Patients II and III were typical of post-TB lung disease. This was an expected observation in these patients since persistence of pulmonary cavities after successful pulmonary TB treatment is very common [4] and these cavities are thought to harbor mold spores leading to fungal colonization [11]. So, since patient II was diagnosed and treated four times for PTB, it is possible that not all of these four times were confirmed PTB but were managed as smear-negative or culture-negative TB based on the high clinical suspicion of TB. Moreover, case II appears to be semi-invasive aspergillosis.

CPA is heavily underdiagnosed and misdiagnosed in resource-limited settings where rapid diagnostics are unavailable [25]. Previously treated TB is the most common risk factor for the development of CPA even in the developed world $[4,26]$. The burden of CPA attributed to healed TB lesions alone has been estimated at 3347 cases in Uganda [8]. In high tuberculosis burden nations, exclusion of active tuberculosis is the most important first step in the diagnosis of CPA. This is often not an issue, as highly sensitive molecular point-of-care tests, such as the GeneXpert MTB/RIF cartridge-based nucleic acid amplification test, are widely available in Uganda [27]. However, the true burden of post-TB CPA in resource-limited areas endemic for both HIV and TB is not well described, and therefore more epidemiological studies are needed.

A well-designed cross-sectional study conducted in a resource-limited setting (Lagos, Nigeria) with over 70\% of the participants being HIV positive reported an overall CPA prevalence of $8.7 \%, 6.5 \%$ among HIV infected and 14.5\% among HIV-negative participants [25]. Another study conducted in Gulu, Uganda, reported an overall CPA prevalence of $4.9 \%, 3 \%$ among HIV infected and 6.9\% among HIV-negative persons [28]. From these two studies, it appears that CPA may be less frequent in HIV co-infected patients. However, more studies are required to make a concrete conclusion.

As illustrated in the above cases, we have seen patients being subjected to anti-TB medications two or more times even when the sputum test for TB was negative. In addition, obvious cavitary lesions with fungal balls consistent with CPA are treated as active TB lesions because CPA cannot be ruled in. This could be due to the low index of suspicion among clinicians and/or lack of pointof-care fungal diagnostics. We have been able to safely discontinue anti-TBs in patients with negative mycobacterial work-ups who meet the diagnostic criteria for CPA and have commenced them on the appropriate antifungal therapy with an overall good outcome. However, the high cost of itraconazole together with the long duration of treatment is still a major challenge in our country.

Based on the experience and the overwhelming success of LFDs in the diagnosis of a sister fungal infection, cryptococcal meningitis, in resource-limited settings $(29,30)$, if made widely available and accessible, Aspergillus LFD will change the way CPA is diagnosed in resource-limited settings, reducing misdiagnosis and unnecessary use of anti-TB therapy in this population. There is need to advocate for translational research into developing more fungal diagnostics to address the local disease burden [31]. In conclusion, the availability of simple clinical diagnostic criteria for CPA and an LFD have the potential to reduce misdiagnosis of CPA and in turn improve CPA treatment outcomes in resource-limited settings. 


\section{Abbreviations}

CPA: Chronic pulmonary aspergillosis; LFD: Lateral flow device; IgG: Immunoglobulin G; PTB: Pulmonary tuberculosis; TB: Tuberculosis; HIV: Human immunodeficiency virus; IgM: Immunoglobulin M; WHO: World Health Organization; COPD: Chronic obstructive pulmonary disease; ICS: Intercostal space; CT: Computed tomography; TDF/3TC/DTG: Tenofovir disoproxil fumarate/ lamivudine/ dolutegravir; CD4: Cluster of differentiation 4; BP: Blood pressure; SPO2: Peripheral capillary oxygen saturation; $\mathrm{mmHg}$ : Millimetre of mercury; MTB/RIF: Mycobacteria tuberculosis/rifampicin resistance; CE: Conformité Européene; ICT: Immuno-chromatographic test; BALF: Bronchoalveolar lavage fluid.

\section{Supplementary Information}

The online version contains supplementary material available at https://doi. org/10.1186/s13256-021-02721-9.

Additional file 1: CARE Checklist. File contains a CARE Checklist of information to include when writing a case report.

\section{Acknowledgements}

RK is currently supported through the DELTAS Africa Initiative grant DEL15-011 to THRiVE-2, from the Wellcome Trust grant 107742/Z/15/Z and the government of the United Kingdom.

\section{Authors' contributions}

FB and RK conceived the manuscript. FB, RK and AK drafted the manuscript. FB, RK, AK, BJK and LN contributed to the critical review of the manuscript. All authors have read and approved the manuscript.

\section{Funding}

This research did not receive any specific grant from funding agencies in the public, commercial or not-for-profit sectors.

\section{Availability of data and materials}

All data generated or analyzed during this study are included in this published article and its supplementary information files. The authors confirm that all data underlying the findings are fully available without restriction and can be accessed by contacting Mr. Richard Kwizera (kwizerarichard@ymail.com).

\section{Ethics approval and consent to participate}

Written informed consent was obtained from all the three participants. Other confirmed cases that did not give consent were excluded from this manuscript.

\section{Consent for publication}

Written informed consent was obtained from the patients for publication of this case report and any accompanying images. A copy of the written consent is available for review by the Editor-in-Chief of this journal.

\section{Competing interests}

The authors declare that they have no competing interests.

\section{Author details \\ ${ }^{1}$ Department of Research, Infectious Diseases Institute, College of Health Sciences, Makerere University, P.O.BOX, 22418 Kampala, Uganda. ${ }^{2}$ Makerere University Lung Institute, College of Health Sciences, Makerere University, Kampala, Uganda. ${ }^{3}$ Department of Medicine, Makerere University College of Health Sciences, Makerere University, Kampala, Uganda. ${ }^{4}$ Department of Medical Microbiology \& Immunology, Faculty of Medicine, Gulu University, Gulu, Uganda.}

Received: 19 June 2020 Accepted: 4 February 2021

Published online: 30 March 2021

\section{References}

1. Keeler E, Perkins MD, Small P, Hanson C, Reed S, Cunningham J, Aledort JE, Hillborne L, Rafael ME, Girosi F, et al. Reducing the global burden of tuberculosis: the contribution of improved diagnostics. Nature 2006:444(Suppl 1):49-57. https://doi.org/10.1038/nature05446.

2. WHO. Global tuberculosis report 2020. Geneva: World Health Organization, 2020 Contract No.: ISBN 978-92-4-001313-1.

3. van Kampen SC, Wanner A, Edwards M, Harries AD, Kirenga BJ, Chakaya J, Jones R. International research and guidelines on post-tuberculosis chronic lung disorders: a systematic scoping review. BMJ global health. 2018;3(4):e000745. https://doi.org/10.1136/bmjgh-2018-000745.

4. Denning DW, Riniotis K, Dobrashian R, Sambatakou H. Chronic cavitary and fibrosing pulmonary and pleural aspergillosis: case series, proposed nomenclature change, and review. Clin Infect Dis. 2003;37(Suppl 3):S265-80. https://doi.org/10.1086/376526.

5. Hayes GE, Denning DW. Frequency, diagnosis and management of fungal respiratory infections. Curr Opin Pulmonary Med. 2013;19(3):259-65. https://doi.org/10.1097/MCP.0b013e32835f1ad1.

6. Bongomin F, Gago S, Oladele RO, Denning DW. Global and multi-national prevalence of fungal diseases_estimate precision. J Fungi. 2017;3(4):57.

7. Bongomin F, Asio LG, Baluku JB, Kwizera R, Denning DW. Chronic pulmonary aspergillosis: notes for a clinician in a resource-limited setting where there is no mycologist. J Fungi. 2020;6(2):75. https://doi.org/10.3390/jof60 20075.

8. Parkes-Ratanshi R, Achan B, Kwizera R, Kambugu A, Meya D, Denning DW. Cryptococcal disease and the burden of other fungal diseases in Uganda; Where are the knowledge gaps and how can we fill them? Mycoses. 2015;58:85-93. doi: https://doi.org/10.1111/myc.12387.

9. Bongomin F. Post-tuberculosis chronic pulmonary aspergillosis: an emerging public health concern. PLoS Pathog. 2020;16(8):e1008742. https://doi.org/10.1371/journal.ppat.1008742.

10. Denning DW, Pleuvry A, Cole DC. Global burden of chronic pulmonary aspergillosis as a sequel to pulmonary tuberculosis. Bull World Health Organ. 2011;89(12):864-72. https://doi.org/10.2471/BLT.11.089441.

11. Kwizera R, Parkes-Ratanshi R, Page ID, Sekaggya-Wiltshire C, Musaazi J, Fehr J, Castelnuovo B, Kambugu A, Denning DW. Elevated Aspergillusspecific antibody levels among HIV infected Ugandans with pulmonary tuberculosis. BMC Pulm Med. 2017;17(1):149. https://doi.org/10.1186/ s12890-017-0500-9.

12. WHO. Global tuberculosis report 2019. Geneva: World Health Organization, 2019 Contract No.: ISBN 978-92-4-156571-4

13. Kwizera R, Bongomin F, Lukande R. Deep fungal infections diagnosed by histology in Uganda: a 70-year retrospective study. Medical mycology. 2020:4:1-9. doi: https://doi.org/10.1093/mmy/myaa018.

14. Denning DW, Page ID, Chakaya J, Jabeen K, Jude CM, Cornet M, AlastrueyIzquierdo A, Bongomin F, Bowyer P, Chakrabarti A, et al. Case Definition of Chronic Pulmonary Aspergillosis in Resource-Constrained Settings. Emerg Infect Dis. 2018;24(8):45. doi: https://doi.org/10.3201/eid24 08.171312 .

15. Takazono T, Izumikawa K. Recent Advances in Diagnosing Chronic Pulmonary Aspergillosis. Frontiers in microbiology. 2018;9:1810. https://doi org/10.3389/fmicb.2018.01810.

16. Bongomin F, Kwizera R, Atukunda A, Kirenga BJ. Cor pulmonale complicating chronic pulmonary aspergillosis with fatal consequences: experience from Uganda. Med Mycol Case Rep. 2019;25:22-4. https://doi. org/10.1016/j.mmcr.2019.07.001.

17. Kwizera R, Katende A, Teu A, Apolot D, Worodria W, Kirenga BJ, Bongomin F. Algorithm-aided diagnosis of chronic pulmonary aspergillosis in lowand middle-income countries by use of a lateral flow device. Eur J Clin Microbiol Infect Dis. 2020;39(1):1-3. https://doi.org/10.1007/s10096-01903782-x.

18. Stucky Hunter E, Richardson MD, Denning DW. Evaluation of LDBio Aspergillus ICT Lateral Flow Assay for lgG and IgM Antibody Detection in Chronic Pulmonary Aspergillosis. J Clin Microbiol. 2019;57(9):e00538-e619. https://doi.org/10.1128/JCM.00538-19.

19. Piarroux RP, Romain T, Martin A, Vainqueur D, Vitte J, Lachaud L, Gangneux JP, Gabriel F, Fillaux J, Ranque S. Multicenter evaluation of a novel immunochromatographic test for anti-aspergillus IgG detection. Front Cell Infect Microbiol. 2019;9:12. https://doi.org/10.3389/fcimb.2019.00012

20. Hunter ES, Richardson MD, Denning DW. Evaluation of LD Bio Aspergillus ICT lateral flow assay for lgG and IgM antibody detection in chronic pulmonary aspergillosis. J Clin Microbiol. 2019;538:19.

21. Salzer HJF, Prattes J, Flick H, Reimann M, Heyckendorf J, Kalsdorf B, Obersteiner S, Gaede Kl, Herzmann C, Johnson GL, et al. Evaluation of 
galactomannan testing, the aspergillus-specific lateral-flow device test and levels of cytokines in bronchoalveolar lavage fluid for diagnosis of chronic pulmonary aspergillosis. Front Microbiol. 2018;9:2223. https://doi. org/10.3389/fmicb.2018.02223.

22. Nam HS, Jeon K, Um SW, Suh GY, Chung MP, Kim H, Kwon OJ, Koh WJ. Clinical characteristics and treatment outcomes of chronic necrotizing pulmonary aspergillosis: a review of 43 cases. IJID. 2010;14(6):e479-82. https://doi.org/10.1016/j.jiji.2009.07.011.

23. Kwizera R, Bongomin F, Meya DB, Denning DW, Fahal AH, Lukande R. Mycetoma in Uganda: A neglected tropical disease. PLoS neglected tropical diseases. 2020;14(4):e0008240. https://doi.org/10.1371/journ al.pntd.0008240.

24. Bongomin F, Erima B, Kwizera R, Odongo-Aginya El. Online learning resources enhanced teaching and learning of medical mycology among medical students in Gulu University. Uganda Education Research International. 2020;2020:1-5. https://doi.org/10.1155/2020/9468241.

25. Oladele R, Irurhe N, Foden P, Akanmu A, Gbaja-Biamila T, Nwosu A, Ekundayo H, Ogunsola F, Richardson M, Denning D. Chronic pulmonary aspergillosis as a cause of smear-negative TB and/or TB treatment failure in Nigerians. Int J Tuberc Lung Dis. 2017;21(9):1056-61.

26. Smith NL, Denning DW. Underlying conditions in chronic pulmonary aspergillosis including simple aspergilloma. Eur Respir J. 2011;37(4):86572. https://doi.org/10.1183/09031936.00054810.

27. Dorman SE, Schumacher SG, Alland D, Nabeta P, Armstrong DT, King B, Hall SL, Chakravorty S, Cirillo DM, Tukvadze N, et al. Xpert MTB/RIF Ultra for detection of Mycobacterium tuberculosis and rifampicin resistance: a prospective multicentre diagnostic accuracy study. Lancet Infect Dis. 2018;18(1):76-84. https://doi.org/10.1016/S1473-3099(17)30691-6.

28. Page ID, Byanyima R, Hosmane S, Onyachi N, Opira C, Richardson M, Sawyer R, Sharman A, Denning DW. Chronic pulmonary aspergillosis commonly complicates treated pulmonary tuberculosis with residual cavitation. Eur Respir J. 2019;53(3):1801184. https://doi.org/10.1183/13993 003.01184-2018.

29. Boulware DR, Rolfes MA, Rajasingham R, von Hohenberg M, Qin Z, Taseera K, Schutz C, Kwizera R, Butler EK, Meintjes G, et al. Multisite validation of cryptococcal antigen lateral flow assay and quantification by laser thermal contrast. Emerg Infect Dis. 2014;20(1):45-53. https://doi. org/10.3201/eid2001.130906.

30. Williams DA, Kiiza T, Kwizera R, Kiggundu R, Velamakanni S, Meya DB, Rhein J, Boulware DR. Evaluation of fingerstick cryptococcal antigen lateral flow assay in HIV-infected persons: a diagnostic accuracy study. Clin Infect Dis. 2015;61 (3):464-7. https://doi.org/10.1093/cid/civ263.

31. Kwizera R, Mande E, Omali D, Okurut S, Nabweyambo S, Nabatanzi R, Nakanjako D, Meya DB. Translational research in Uganda: linking basic science to bedside medicine in a resource limited setting. J Trans Med. 2021;19(1):76. https://doi.org/10.1186/s12967-021-02747-z.

\section{Publisher's Note}

Springer Nature remains neutral with regard to jurisdictional claims in published maps and institutional affiliations.
Ready to submit your research? Choose BMC and benefit from:

- fast, convenient online submission

- thorough peer review by experienced researchers in your field

- rapid publication on acceptance

- support for research data, including large and complex data types

- gold Open Access which fosters wider collaboration and increased citations

- maximum visibility for your research: over $100 \mathrm{M}$ website views per year

At BMC, research is always in progress.

Learn more biomedcentral.com/submissions 